\title{
THE PERFORMANCE OF MONOLITHIC STRUCTURED CALCIUM OXIDE FOR BIODIESEL
}

\author{
S.R. Azman, M. Ismail ${ }^{*}$, A.A.H. Kadhum and Z. Yaakob \\ Faculty of Engineering and Built Environment \\ Department of Chemical and Process Engineering \\ Universiti Kebangsaan Malaysia, \\ 43600 Bandar Baru Bangi, Selangor, Malaysia \\ *Email: manal@eng.ukm.my \\ Phone: +60 389216404; Fax: +60 389216148
}

\begin{abstract}
A novel catalytic packing in biodiesel production using a monolithic structured support catalyst is studied. Calcium oxide $(\mathrm{CaO})$ is chosen as the wash coat due to its well established property as a good catalyst. The experiment for the monolithic $\mathrm{CaO}(4 \mathrm{~cm}$

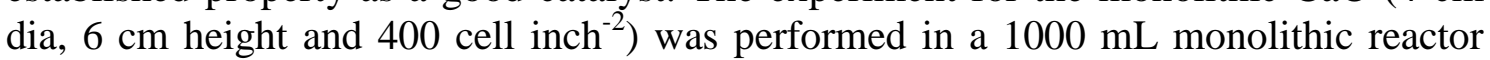
while the $\mathrm{CaO}$ powder experiment was carried out in a $100 \mathrm{~mL}$ three-necked glass reactor. Under optimum conditions, the monolithic catalyst produced $73.17 \%$ of biodiesel and for uncoated $\mathrm{CaO}$ on monolith still exhibited some catalytic activity ( $26.7 \%$ conversion). Although a high conversion of $98 \%$ was attained in powder form, the monolithic catalyst has sufficient capacity and capability to be a viable alternative that provides a structured arrangement for biodiesel production. The active property in the monolithic material, designed to achieve high cell density for a larger geometrical surface area, leads to a more efficient catalyst utilization and allows for a cleaner process overall compared to the conventional technology.
\end{abstract}

Keywords: Biodiesel; calcium oxide; coating; monolith; structured support.

\section{INTRODUCTION}

The equilibrium of the ecology may become unstable due to the poor quality of air, water pollution and soil contamination. The pollution index is always in the medium to high risk level, which leads to many man-made disasters such as acid rain, soil erosion, haze, etc. In the case of air pollution, common causes are vehicle exhaust gases, unplanned burning and felling of trees [1]. Therefore, one way to reduce the problem is by switching to biodiesel as an alternative clean fuel. As mentioned in many reviews [27], biodiesel is an alternative fuel that reduces the consumption of fossil resource and also our sole dependence on it. This can alleviate the level of air pollution, lowering the effect of global warming and enhancing energy sustainability [8-11]. In other words, biodiesel is a renewable, biodegradable, environmentally benign, energy-efficient, substitute fuel which can fulfill energy security needs without sacrificing engines' operational performance [2, 12, 13]. Environmentalists also choose biodiesel because the carbon dioxide that it produces on burning will be absorbed naturally and recycled without an overall net increase in the atmospheric $\mathrm{CO}_{2}$ inventory [14]. Furthermore, biodiesel is denoted as a major contributor to multiple economic sections through either export or import. Due to the rising cost of gasoline and diesel, many consumers and 
businesses are eager to make the switch to biodiesel to run their diesel-powered vehicles or generate electricity. Biodiesels are derived from sources such as vegetable oils, fats and non-edible oils. The most widely used industrial method for the commercial production of biodiesel from vegetable oils/fats is a base catalyzed transesterification process using $\mathrm{KOH}$ or $\mathrm{NaOH}$ as the homogeneous catalyst and $\mathrm{MeoH}$ as the lower alcohol [15] to produce methyl ester. If the catalyst phase (solid) is different from the reactant phase, it is called heterogeneous catalytic transesterification [3]. Considering the economic production cost and clean environment, heterogeneous catalysts are the preferred catalyst type and are included under Green Technology [3]. This is due to the following attributes: (1) the catalyst can be recycled (reused); (2) a much reduced amount of wastewater is produced; and (3) the separation of biodiesel and glycerol is much easier. Such attributes have been studied by Marchetti, Miguel [16], who performed a techno-economic analysis of four different catalyst types for biodiesel production; acid and basic homogeneous catalysts, heterogeneous catalysis and supercritical technology. They concluded that the heterogeneous process showed the best economic indicators due to the low amount to treat, the smaller amount of equipment needed and the greater purity of the glycerol.

The importance of achieving an efficient heterogeneous process has provided the impetus to finding ways to overcome certain drawbacks. Among the challenges are the separation between solid catalyst and products and catalyst attrition that makes the performance less efficient on a larger, continuous scale. As an answer to those challenges, monolithic structured support catalysts are addressed in this study, as they are already well known in the automotive industry as exhaust gas converters and work superbly in the oleochemical-based hydrogenation reaction process. A ceramic monolith material made of cordierite, $2 \mathrm{MgO} .2 \mathrm{Al}_{2} \mathrm{O}_{3} .5 \mathrm{SiO}_{2}$, is applied in this study since it offers the advantages of high surface-to-volume ratio, large open frontal area, low thermal mass, low heat capacity, low thermal expansion, high oxidation resistance, high strength and high operational temperature [17]. By applying this technology, it is possible to eliminate the filtration step in the heterogeneous process as well as neutralization and the washing of the catalyst in the homogeneous process. Besides that, the attrition between the catalyst and reactant will be minimized, since the only phase transition occurs in the small cell size in the monolith structure. In fact, the reduction of steps will compensate for the higher cost of the catalyst. Furthermore, this approach is the first step in biodiesel production that can be compared to the current automotive industry in terms of the monolithic configuration. In the present study, we selected calcium oxide as the most promising heterogeneous catalyst, since it is known as the most stable catalyst among the metal oxide types and is well established from many reviews. The behaviour of calcium oxide was studied and the optimum substrate was deposited over a cordierite substrate to generate a monolithic structure. This was tested in a monolithic reactor where monolithic catalyst structures are attached to a stirrer to induce the reaction to take place in the monolith cell. In addition, characterizations of the catalyst were also performed by means of X-ray diffraction (XRD), various pressure surface electron microscopy (VPSEM) and a catalyst strength test.

\section{EXPERIMENT METHODS}

This section describes the materials and methods used in this study. In addition, the preparation of the apparatus and experimental method are also discussed to ascertain the material synthesis involved. 


\section{Catalyst Preparation}

The uses of the calcium oxide, $\mathrm{CaO}$, system need to be established in the transesterification reaction prior to applying it on the surface of the monolithic structure support. Therefore, in order to match the result with the previous works, some preliminary experiments were conducted. The $\mathrm{CaO}$ powders were treated by calcination with nitrogen gas at three different temperatures: $550{ }^{\circ} \mathrm{C}, 700{ }^{\circ} \mathrm{C}$ and $800{ }^{\circ} \mathrm{C}$ for 5 hours. For monolithic catalyst, cordierite $\left(3 \mathrm{SiO}_{2}: 2 \mathrm{Al}_{2} \mathrm{O}_{3}: 2 \mathrm{MgO}\right)$ with a honeycomb structure (400 cpsi) was used as the ceramic substrate. The substrate, with a cylindrical shape (40 $\mathrm{mm}$ diameter, $60 \mathrm{~mm}$ height) was washed with acetone at $60{ }^{\circ} \mathrm{C}$ and dried overnight at $80{ }^{\circ} \mathrm{C}$. A slurry-coating technique was used to coat an active $\mathrm{CaO}$ catalyst on the monolith structure, where pseudo-boehmite as a binder and washcoat solution were prepared. This will make the catalyst work more efficiently because the diffusion distance towards the active spatial area will be small. Firstly, pseudo-boehmite was prepared from aluminium hydroxide, $\mathrm{Al}(\mathrm{OH})_{3}$, urea and $0.3 \mathrm{M}$ of nitric acid in a weight ratio of 2:1:5. The mixture was agitated at $600 \mathrm{rpm}$ for 8 hours and reached a final $\mathrm{pH}$ of 3-5. The acid makes the alumina form positively-charged agglomerates, which repel each other, and prevents the formation of large three-dimensional alumina networks. Therefore, the addition of the polar urea helps keep a low viscosity sol by preventing the gelation of the $\mathrm{Al}(\mathrm{OH})_{3}$ becoming worse [18]. After that, when the binder was ready, the washcoat solutions were formed, where the composition of the slurry was $\mathrm{CaO}$ catalyst, pseudo-boehmite slurry and deionized water in a weight ratio of 5:1:4. The mixture was then agitated at $450 \mathrm{rpm}$ for 4 hours until a homogeneous solution was observed. Then, the slurry solution was ready to use. The bare cordierite monolith was half-dipped in the slurry coating mixture and maintained at 60 seconds. Then, the excess liquids were shaken out of the monolith and the blocked channels were cleared using pressurized air blow. After that, they were dried at $200{ }^{\circ} \mathrm{C}$ for 2 hours. These dipping procedures were repeated until complete catalyst loading was achieved. Finally, the samples were calcined at $550{ }^{\circ} \mathrm{C}$ for 5 hours (reasonable treated temperature).

\section{Catalyst Characterization}

Monolithic structured catalyst characterization was performed with an XRD and the diffractogram images were recorded for $2 \theta$ between $3^{\circ}$ and $80^{\circ}$ on a Bruker AXS D8 Advance diffractometer employing a scanning rate of $0.02 \%$ with $\mathrm{Cu}-\mathrm{K} \alpha$ radiation $(\lambda=$ 1.5418). The morphology of the deposited catalyst layer was obtained by various pressure scanning electron microscopy (VPSEM) with EVO MA10, Carl Zeiss SUPRA 55 equipment. The catalyst adhesion on the substrate was estimated by calculating the weight loss of a catalyst-coated sample treated in an ultrasonic bath at maximum frequency for $30 \mathrm{~min}$.

\section{Catalytic Test}

The treated catalyst powders were investigated in a $100 \mathrm{~mL}$ glass batch reactor and the catalysis activities were measured at three varying parameters. The reactions were studied at $65{ }^{\circ} \mathrm{C}, 900 \mathrm{rpm}$, different reaction times (1, 2, 3, 4, and 5 hours), different molar alcohol/oil ratios $(8,10,13,15,18$ and 20) and different catalyst weights $(1,2,4$, 6 and $8 \mathrm{wt} \%$ ). Then optimized parameters were chosen, which were a 20 molar ratio alcohol/oil and $4 \mathrm{wt} \%$ of catalyst weight, and they were subsequently tested in the 
monolithic reactor, as shown in Figure 1. The monolithic catalyst coated with $\mathrm{CaO}$ and activated at $550{ }^{\circ} \mathrm{C}$ was configured in the form of a stirrer and attached to the mixer housed inside the monolithic reactor. The raw materials were fed into the reactor and then the system was heated up until the reaction temperature was reached. After 5 hours of reaction, the sample was taken and methanol and biodiesel were separated using a separator funnel. Raw biodiesel was collected and washed with warm water to get the pure biodiesel before proceeding to analysis.

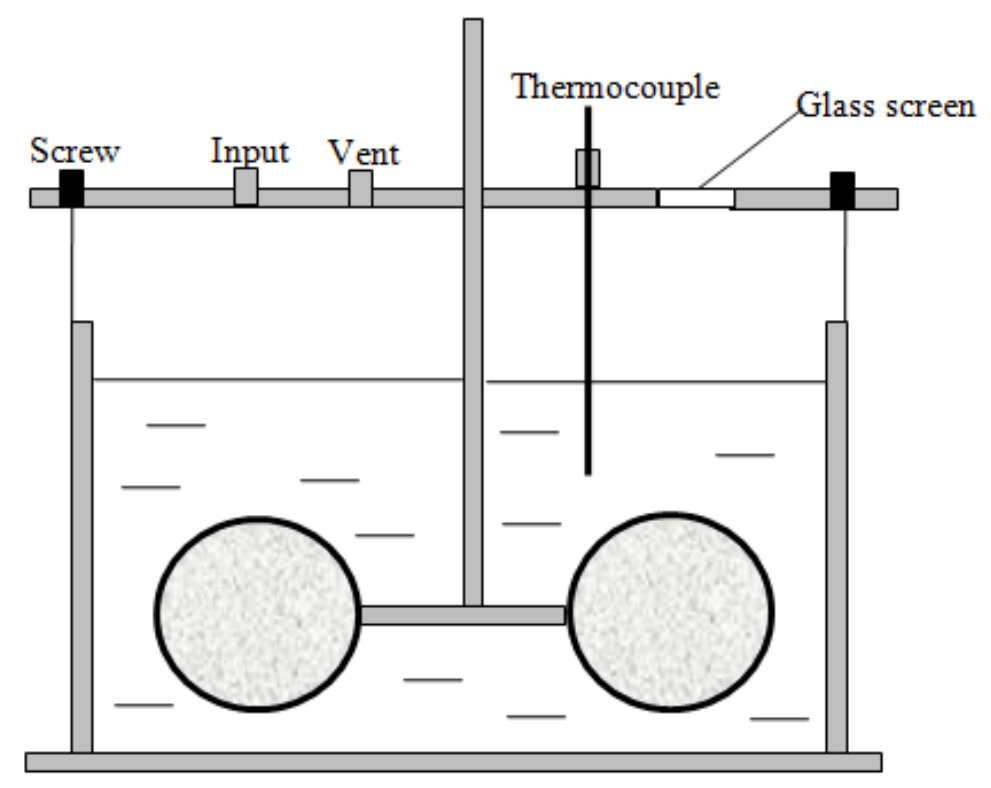

Figure 1. Schematic diagram of monolithic reactor.

\section{Biodiesel Analysis}

The analysis procedures were based on ASTM D6584. The weight percentage of methyl ester in the product was determined using an SRI Gas Chromatograph equipped with MXT® biodiesel TG column and flame ionization detector (FID). Nitrogen was used as the carrier gas at a flow rate of $3 \mathrm{~mL} / \mathrm{min}$. The column temperature was increased from 50 to $180{ }^{\circ} \mathrm{C}$ at a rate of $15{ }^{\circ} \mathrm{C} / \mathrm{min}$, to $230{ }^{\circ} \mathrm{C}$ at a rate of $7{ }^{\circ} \mathrm{C} / \mathrm{min}$, and to $380{ }^{\circ} \mathrm{C}$ at a rate of $30^{\circ} \mathrm{C} / \mathrm{min}$. The column was maintained at this temperature for $20 \mathrm{~min}$. One hundred milligrams of the separated biodiesel samples were derivatized by $100 \mu \mathrm{L}$ of $\mathrm{N}$-methyl-N-trimethylsilyltrifluoro-acetamide (MSFA) in a $10 \mathrm{ml}$ septa-vial. The mixture was shaken well and allowed to stay at room temperature for 15-20 min. Approximately $8 \mathrm{~mL}$ of $\mathrm{n}$-heptane was added and mixed well. $1 \mu \mathrm{L}$ of the reaction mixture was injected into the gas chromatograph. Mono-, di-, and triglycerides were determined by comparison with mono-, di- and tri-olein standards.

\section{RESULTS AND DISCUSSION}

\section{Transesterification of Oil Using CaO Powder}

The $\mathrm{CaO}$ catalysts were effectively used for the biodiesel production. Their activities for transesterification of oil were measured by performing a batch-type reaction and the 
influences of various reaction parameters on oil conversion are illustrated in the respective figures. Typically, $\mathrm{CaO}$ requires a thermal activation to remove the adsorbed $\mathrm{CO}_{2}$ and moisture. In the transesterification of oil, thermally activated $\mathrm{CaO}$ at $550{ }^{\circ} \mathrm{C}$ demonstrated a good yield $\left(98.21 \%\right.$ ) at a reaction setting of $60{ }^{\circ} \mathrm{C}$ and $15: 1$ methanol/oil molar ratio, as shown in Figure 2. Thus, $\mathrm{CaO}$ treated at this temperature was used for monolithic incorporation. However, when the reaction was done by using samples thermally activated at temperatures of $700{ }^{\circ} \mathrm{C}$ and $800{ }^{\circ} \mathrm{C}$, the catalyst efficiency deteriorated and its components leached into the reaction mixture, making the catalysts separation process more tedious and not preferred as the optimum condition. This may be due to the increase of poisoning material such as iron (II) oxide, $\mathrm{Fe}_{2} \mathrm{O}_{3}$. In fact, biodiesel is more sensitive to corrosion than diesel. Since iron (II) oxide, $\mathrm{Fe}_{2} \mathrm{O}_{3}$, is one of the corrosive compounds, it is subject to a higher corrosion attack during reaction [19]. Besides, in the presence of $\mathrm{Fe}_{2} \mathrm{O}_{3}$, the catalysts showed decreased activity when alcohol was used, which was attributed to the steric effects on the catalyst activity. Furthermore, active sites of $\mathrm{CaO}$ are easily blocked by adsorbing intermediates (diglyceride, monoglyceride) or product [20] causing $\mathrm{CaO}$ leaching.

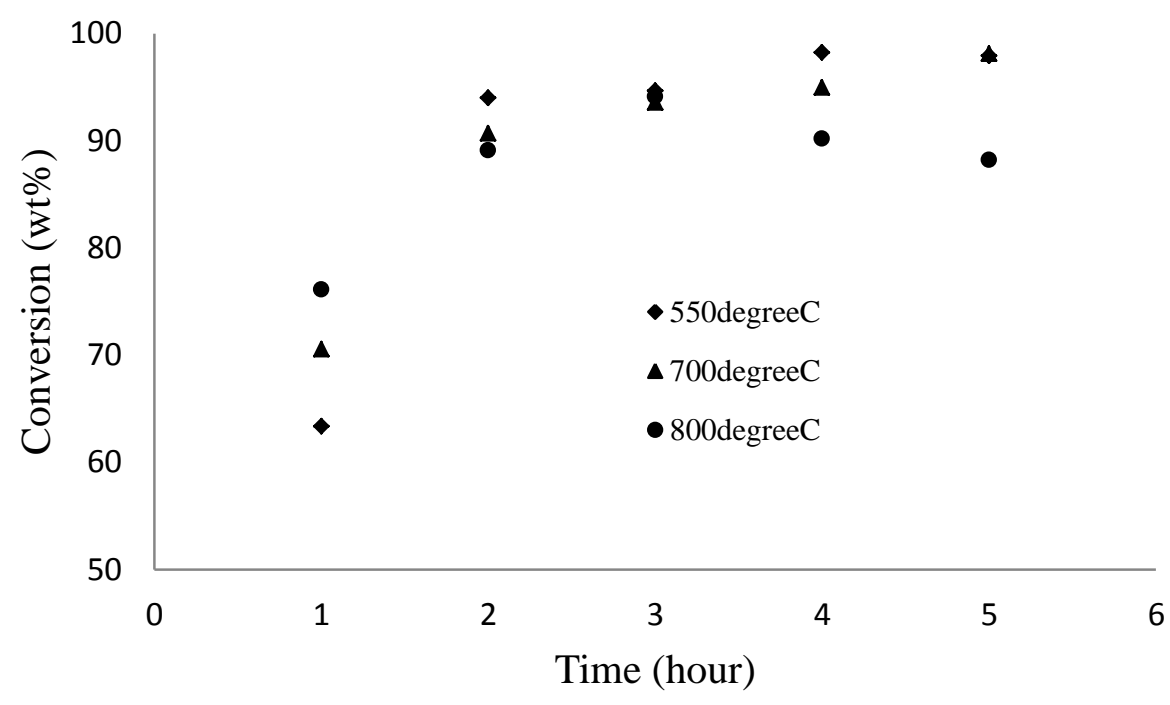

Figure 2. Influence of calcination temperature.

The maximum conversion was obtained at 4 hours using $\mathrm{CaO}$ powder catalyst which was approximately 98\%, as is evident from the results shown in Figure 3. Even though the reaction time was longer, i.e., 2-4 hours, compared to the homogeneous catalyst such as $\mathrm{NaOH}, \mathrm{CaO}$ has an advantage in terms of catalyst cost due to its cheap price, minor toxicity and general availability [3]. In addition, $\mathrm{CaO}$ is a heterogeneous catalyst that has the general advantages of easy separation from the reaction medium and reusability. Hence, even though the reaction was longer, the process requires neither catalyst recovery nor aqueous treatment, which makes for a simpler production process [21] compared to the homogeneous catalyst, which is more tedious and costly for the treatment process. 


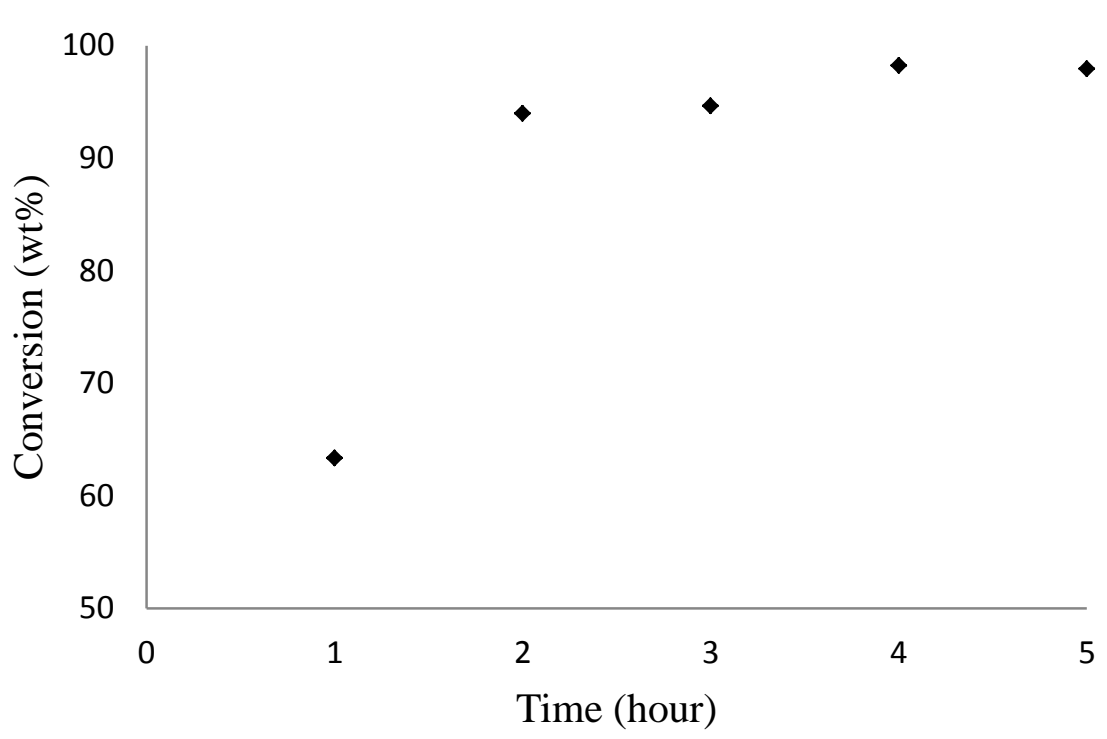

Figure 3. Effect of reaction time.

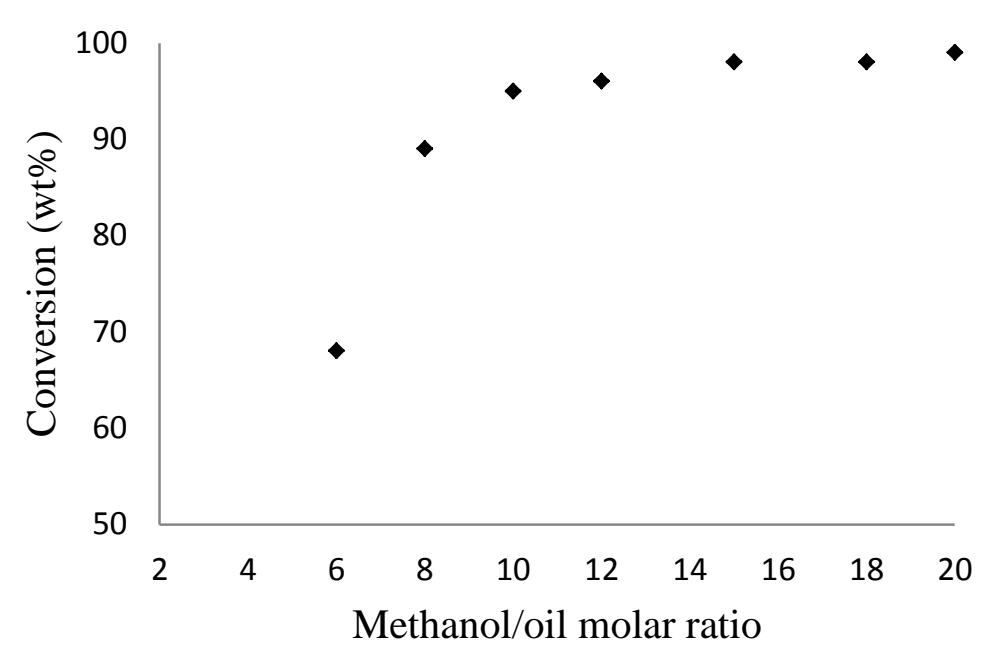

Figure 4. Effect of molar ratio.

The $\mathrm{CaO}$ powder catalyst yielded the best result at a methanol/oil molar ratio of 15, as seen from Figure 4. Further increase in the molar ratio did not cause any appreciable change in the activity. The performance of $\mathrm{CaO}$ was slightly better at a higher molar ratio, but the reasonable amount at the methanol/oil molar ratio of 15 was chosen. This is because, even though the process involved a high methanol/oil molar ratio, excess methanol could be recovered at the end and was used for successful reactions [22]. The overall reaction is:

$$
\mathrm{TG}+3 \mathrm{OH} \stackrel{\text { catalyst }}{\longleftrightarrow} 3 \mathrm{R}^{\prime} \mathrm{CO}_{2}-\mathrm{R}+\mathrm{GL}
$$

where

TG is triglyceride; $\mathrm{OH}$ is alcohol

$3^{\prime} \mathrm{RCO}_{2}-\mathrm{R}$ is methyl ester; GL is glycerol 
3 mole of alcohol will react with 1 mole of triglyceride to produce 3 mole of methyl ester and 1 mole of glycerol. Based on the result, the maximum molar ratio of methanol is 15 , which was in excess of the stoichiometric 3 mole alcohol, but was necessary to achieve $98 \%$ conversion. When the molar ratio of methanol was increased, the conversion remained the same. Around $20-25 \%$ of the unreacted methanol was recovered, to be used in the next successive reactions.

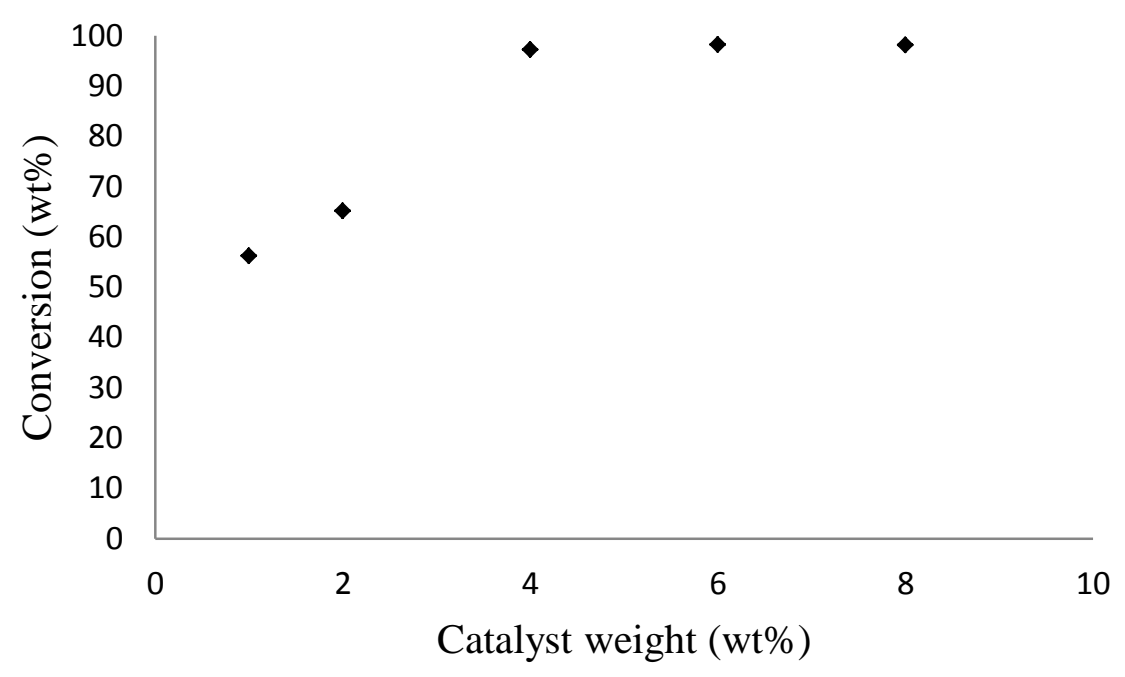

Figure 5. Effect of catalyst weight.

The catalyst/oil weight ratio was increased step by step and the maximum conversion was attained at a catalyst weight of $6 \mathrm{wt} \%$. Thereafter, the activity was observed to be decreasing with increase in the catalyst amount, as in Figure 5. Hence, the reasonable catalyst weight of $\mathrm{CaO}$ powder coated on the monolith structure support could be around 4-6 wt $\%$ to get the maximum conversion. Besides that, since $\mathrm{CaO}$ is essentially low cost, reusable, and easy to obtain, while the separation of the catalyst from the reaction mixture is simple, the consumption of a larger amount of $\mathrm{CaO}$ should not cause any economic concern.

\section{Catalyst Characterization}

Figure 6 presents the X-ray diffractograms for the samples. Peaks at $2 \theta$ of 26.37, 53.81, 64.1, 67.5 and 79.6 are from $\mathrm{CaO}$ and at graph (b) showing the peak of bare cordierite, which acted as a monolith structured support. When analysing $\mathrm{CaO}$ on the monolith structure, they showed similar peaks to the $\mathrm{CaO}$ powder, with peaks at $2 \theta$ of 26.37 and 53.81. This shows that $\mathrm{CaO}$ is fully coated on the monolith structured support. Then, after reaction, the XRD results showed that $\mathrm{CaO}$ still exists on the monolith structured support surface at peaks $2 \theta$ of 26.7 and 64.1 and a small peak represented bare cordierite. These results indicate that the alkali or alkali earth metal, especially $\mathrm{CaO}$, did react with the cordierite support and it was attached strongly onto the cordierite monolith structured support. 


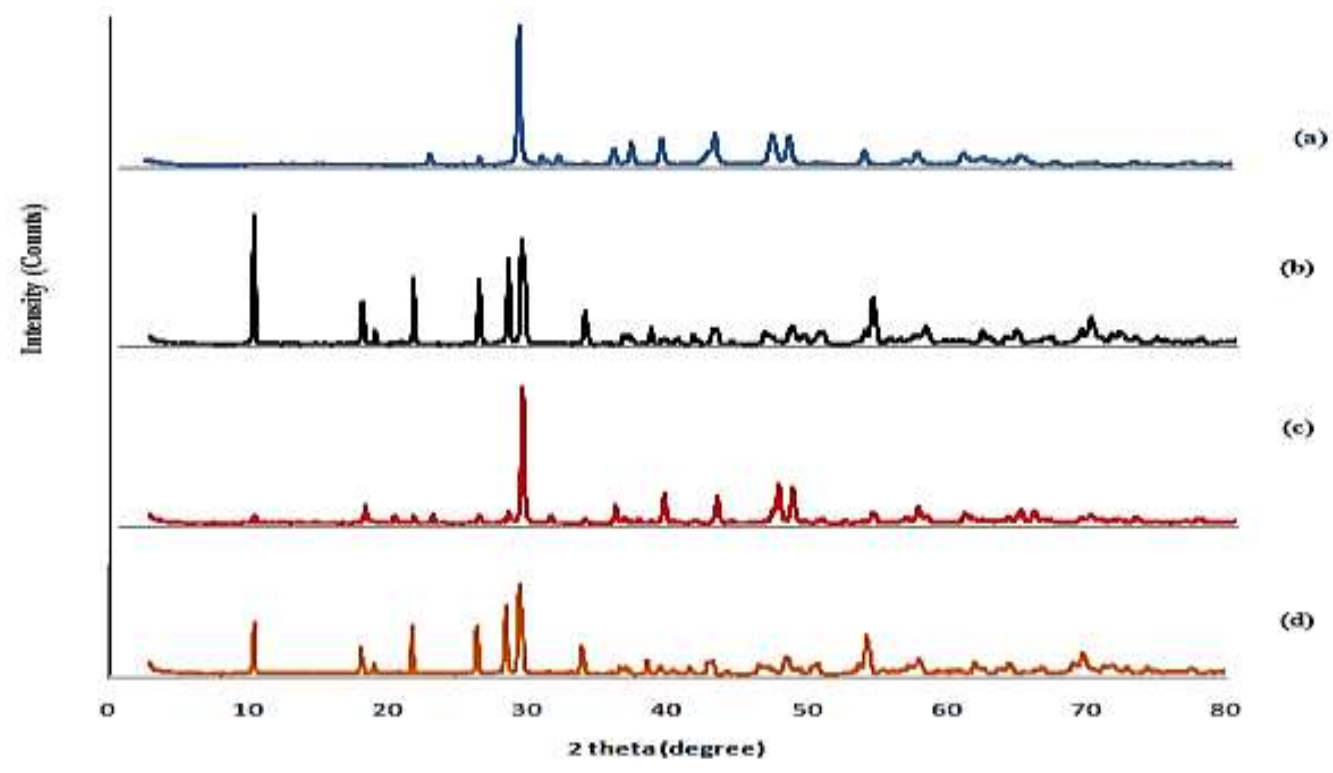

Figure 6. X-ray diffraction. References: (a) $\mathrm{CaO}$; (b) bare cordierite; (c) after coating;

(d) after reaction.

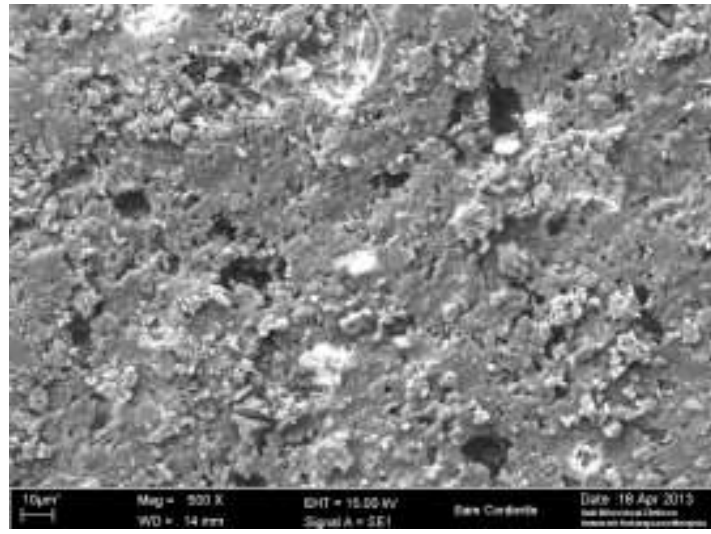

(a)

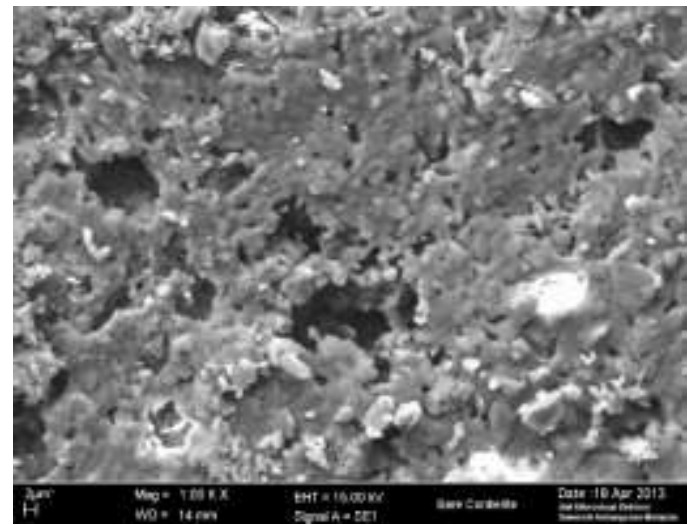

(b)

Figure 7. Example SEM of bare cordierite: (a) view of surface; (b) magnified view of surface: $1000 \mathrm{x}$.

To examine the distribution of the catalyst surface, VPSEM images were taken on the bare cordierite surface (Figure 7) and the coated cordierite with $\mathrm{CaO}$ powder catalyst (Figure 8). The bare cordierite fully coated with $\mathrm{CaO}$ was observed from Figure 8 and large pores of cordierite were recovered. This was obtained after repeating the coating procedures. After the reaction, which was monolithic $\mathrm{CaO}$ catalyst configured as the stirrer in the transesterification reaction, it is observed that $\mathrm{CaO}$ is still attached on the cordierite surface. This indicates that the $\mathrm{CaO}$ is properly attached to the cordierite surface. Furthermore, after performing the adherence test (as described in the experimental section), $99.2 \%$ of the catalytic material remained attached to the monolithic structure support. This result is good, considering that a monolithic catalyst with $99 \%$ adhesion was successfully used in the liquid phase reaction. 


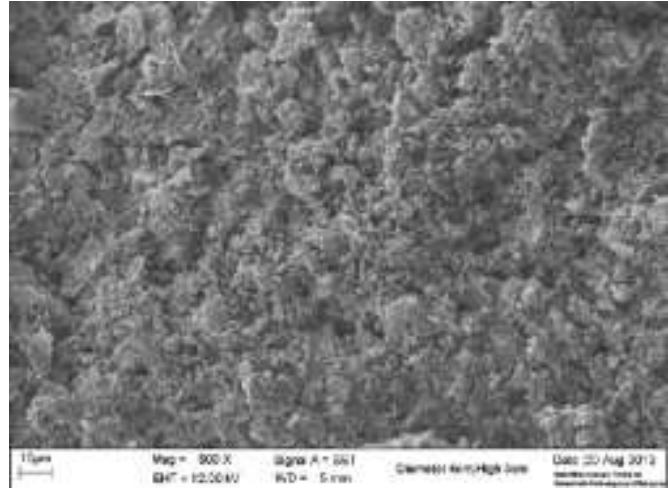

(a)

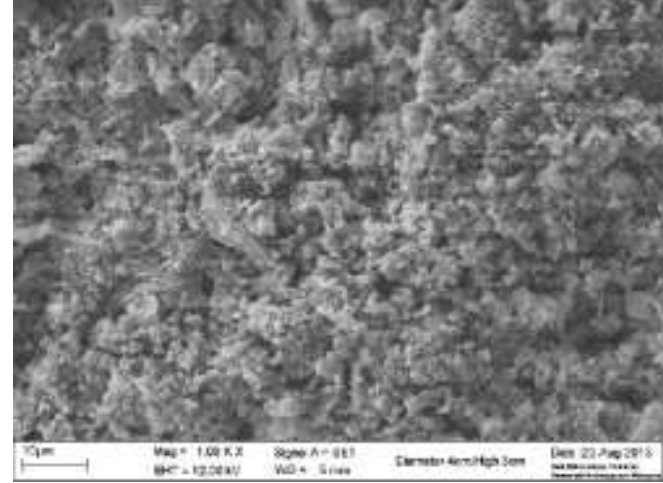

(b)

Figure 8. Example SEM of $\mathrm{CaO}$ coated on cordierite: (a) view of surface; (b) magnified view of surface: $1000 \mathrm{x}$.

Table 1. Operating conditions and FAME conversion results.

\begin{tabular}{lcccc}
\hline Condition & Powder & Monolith 1 & Monolith 2 & Uncoated monolith \\
\hline Catalyst weight (wt\%) & 8 & 4 & 4 & 0 \\
Time (h) & 5 & 5 & 5 & 5 \\
Molar ratio (alcohol/oil) & $15: 1$ & $20: 1$ & $20: 1$ & $20: 1$ \\
FAME (\%) & 98.1 & 73.17 & 71.81 & 26.1 \\
\hline
\end{tabular}

\section{Catalytic Test}

At the optimum condition after which the $\mathrm{CaO}$ powder catalyst was tested, it was found that the suitable parameters for transesterification of oil using the monolithic reactor (Figure 1) were 5 hours of reaction, methanol/oil 20:1 of molar ratio and 4-6 wt\% of catalyst weight and $65{ }^{\circ} \mathrm{C}$ temperature. Table 1 presents the result obtained for the transesterification of oil using the monolithic $\mathrm{CaO}$ reactor. It can be observed that the monolithic $\mathrm{CaO}$ gave a conversion of FAME, even though it was lower than its powder form. Estimates of the geometric external surface area of the monolith and the powdered catalyst indicate that the external surface area of the monolith will be lower than the powdered catalyst. So if the rate had been calculated on the basis of geometric surface area, then the rate for the monolith would have been very much higher. So it may even be that the method of coating the monolith had actually increased the activity of the catalyst, or the cordierite itself exhibited catalytic activity [23]. In addition, the activity of the monolithic catalyst is probably limited by external mass-transfer, therefore, it is recommended to prepare a higher cell density monolith. This would have a larger geometrical surface area and thinner walls, resulting in more efficient catalyst utilization [24]. All the catalysts were calcined at $550{ }^{\circ} \mathrm{C}$ for 5 hours in order to improve the stability of the catalyst and to prevent leaching of the active material. In similar conditions, more experiments were then performed with uncoated samples of cordierite monolith, to see if the cordierite itself exhibited any form of catalytic activity. Subsequently, it was found that $26.1 \%$ conversion of FAME was achieved. Hence, this finding would suggest that the cordierite is catalytically active. In many literature reviews, magnesium oxide, $\mathrm{MgO}$, is known to possess the lowest activity as a catalyst due to the weakest basic strength among group II oxides [25]. However, $\mathrm{MgO}$ may still exhibit some activity in the biodiesel production, and this hypothesis was proven in this 
study. In fact, as the structures of cordierite corresponded to $2 \mathrm{MgO}_{2} 2 \mathrm{Al}_{2} \mathrm{O}_{3} .5 \mathrm{SiO}_{2}$, then the $\mathrm{MgO}$ may well influence the conversion of FAME.

\section{CONCLUSIONS}

$\mathrm{CaO}$ powder catalyst was prepared and calcined and it was found that a $550{ }^{\circ} \mathrm{C}$ calcination temperature was chosen as the most suitable treatment. At optimum parameters, monolithic $\mathrm{CaO}$ was prepared, characterized and studied in the transesterification reaction of oil and methanol at $65{ }^{\circ} \mathrm{C}$, with a 20:1 alcohol/oil molar ratio and catalyst load of $4 \mathrm{wt} \%$. It was observed that the $\mathrm{CaO}$ powder catalyst was very active and the findings were in agreement with the literature, i.e., achieving the FAME conversion of $98 \%$. When the monolithic $\mathrm{CaO}$ was compared with powder, the biodiesel produced was $73.17 \%$, which was less, but the material provided a high cell density to give a larger geometrical surface area and thinner walls, resulting in more efficient catalyst utilization and reusability. From the VPSEM studies on the coated monolith, the distribution of the $\mathrm{CaO}$ catalyst with pore size reduction was an interesting accomplishment. in which they are anchored onto the cordierite support. In future work, it is planned to improve the coating method, and to investigate whether the coating process and the method of interaction with the support actually increase the activity of the catalyst. The present work also shows that the monolithic catalyst is suitable as a new alternative catalyst arrangement for the transesterification of oil in the production of biodiesel. Although powder catalysts showed a better final conversion, the monolithic catalyst will allow for a less complex, cost-effective and cleaner process, rendering the full process more competitive compared to the conventional technology.

\section{ACKNOWLEDGEMENTS}

This study was carried out with the aid of a research grant UKM-GUP-2011-289 from Universiti Kebangsaan Malaysia.

\section{REFERENCES}

[1] Environment UU. Urban air quality management In: Caravanos DJ, editor. United Nations Human Settlements Programme. Nairobi: UNEP Urban Environment; 2006.

[2] Chouhan A, Sarma A. Modern heterogeneous catalysts for biodiesel production: a comprehensive review. Renewable and Sustainable Energy Reviews. 2011;15:4378-99.

[3] Refaat A. Biodiesel production using solid metal oxide catalysts. International Journal of Environmental Science \& Technology. 2011;8:203-21.

[4] Taufiq-Yap Y, Lee H, Hussein M, Yunus R. Calcium-based mixed oxide catalysts for methanolysis of Jatropha curcas oil to biodiesel. Biomass and Bioenergy. 2011;35:827-34.

[5] Abbaszadeh A, Ghobadian B, Najafi G, Yusaf T. An experimental investigation of the effective parameters on wet washing of biodiesel purification. International Journal of Automotive and Mechanical Engineering. 2014;9:152537. 
[6] Kapilan N, Ashok Babu TP, Reddy RP. Improvement of performance of dual fuel engine operated at part load. International Journal of Automotive and Mechanical Engineering. 2010;2:200-10.

[7] Soon LB, M. Rus AZ, Hasan S. Continuous biodiesel production using ultrasound clamp on tubular reactor. International Journal of Automotive and Mechanical Engineering. 2013;8:1396-405.

[8] Mat Yasin MH, Mamat R, Sharma KV, Yusop AF. Influence of palm methyl ester (PME) as an alternative fuel in multicylinder diesel engine. Journal of Mechanical Engineering and Sciences. 2012;3:331-9.

[9] Rahim R, Mamat R, Taib MY, Abdullah AA. Influence of fuel temperature on a diesel engine performance operating with biodiesel blended. Journal of Mechanical Engineering and Sciences. 2012;2:226-36.

[10] Kamil M, Rahman MM, Bakar RA. Integrated simulation model for composition and properties of gases in hydrogen fueled engine. International Journal of Automotive and Mechanical Engineering. 2013;8:1242-155.

[11] Kamil M, Rahman MM, Bakar RA. An integrated model for predicting engine friction losses in internal combustion engines. International Journal of Automotive and Mechanical Engineering. 2014;9:1695-708.

[12] Ramasamy D, Yuan GC, Bakar RA, Zainal ZA. Validation of road load characteristic of a sub-compact vehicle by engine operation. International Journal of Automotive and Mechanical Engineering. 2014;9:1820-31.

[13] Kamil M, Rahman MM, Bakar RA. Performance evaluation of external mixture formation strategy in hydrogen fueled engine. Journal of Mechanical Engineering and Sciences. 2011;1:87-98.

[14] Sharma Y, Singh B. Development of biodiesel: current scenario. Renewable and Sustainable Energy Reviews. 2009;13:1646-51.

[15] Semwal S, Arora AK, Badoni RP, Tuli DK. Biodiesel production using heterogeneous catalysts. Bioresource technology. 2011;102:2151-61.

[16] Marchetti J, Miguel V, Errazu A. Techno-economic study of different alternatives for biodiesel production. Fuel Processing Technology. 2008;89:7408.

[17] Cybulski A, Moulijn JA. Structured catalysts and reactors: CRC Press; 2005.

[18] Nijhuis TA, Beers AE, Vergunst T, Hoek I, Kapteijn F, Moulijn JA. Preparation of monolithic catalysts. Catalysis Reviews. 2001;43:345-80.

[19] Fazal M, Haseeb A, Masjuki H. Degradation of automotive materials in palm biodiesel. Energy. 2012;40:76-83.

[20] Fang FZaZ. Biodiesel Production with Solid Catalysts. In: Stoytcheva DM, editor. Biodiesel - Feedstocks and Processing Technologies. Croatia: InTech; 2011.

[21] Cao F, Chen Y, Zhai F, Li J, Wang J, Wang X, et al. Biodiesel production from high acid value waste frying oil catalyzed by superacid heteropolyacid. Biotechnology and bioengineering. 2008;101:93-100.

[22] Yaakob Z, Sukarman ISB, Narayanan B, Abdullah SRS, Ismail M. Utilization of palm empty fruit bunch for the production of biodiesel from Jatropha curcas oil. Bioresource technology. 2012;104:695-700.

[23] Kolaczkowski ST, Asli U, Davidson M. A new heterogeneous $\mathrm{ZnL}_{2}$ catalyst on a structured support for biodiesel production. Catalysis Today. 2009;147:S220S4. 
[24] Nijhuis T, Van Koten G, Moulijn J. Optimized palladium catalyst systems for the selective liquid-phase hydrogenation of functionalyzed alkynes. Applied Catalysis A: General. 2003;238:259-71.

[25] Zabeti M, Wan Daud WMA, Aroua MK. Activity of solid catalysts for biodiesel production: a review. Fuel Processing Technology. 2009;90:770-7. 